
\section{RIMCIS Social Sciences}

\section{Hipatia Press}

www.hipatiapress.com

Instructions for authors, subscriptions and further details:

http://rimcis.hipatiapress.com

\title{
Cuerpos Aliados y Lucha Política: Hacia una Teoría Performativa de la Asamblea
}

Teresa Plaja-Viñas ${ }^{1}$

1) Universidad de Barcelona. España

Date of publication: July $30^{\text {th }}, 2017$

Edition period: July 2017 - November 2017

To cite this article: Plaja-Viñas, T. (2017). Cuerpos Aliados y Lucha Política: Hacia una Teoría Performativa de la Asamblea [Review of the book]. International and Multidisciplinary Journal of Social Sciences, 6(2), 230-231. doi: 10.17583/rimcis.2017.2823

To link this article: http://doi.org/10.17583/rimcis.2017.2823

\section{PLEASE SCROLL DOWN FOR ARTICLE}

The terms and conditions of use are related to the Open Journal System and to Creative Commons Attribution License (CC-BY). 


\section{Review}

Butler, J. (2017). Cuerpos aliados y lucha política. Hacia una teoría performativa de la asamblea (1 $1^{\mathrm{a}}$ edición). Barcelona: Paidós Básica. ISBN 978-84-493-3303-3

Judith Butler es una de las autoras más reconocidas dentro del feminismo por su desarrollo de la Teoría Queer. Con el libro El Género en disputa. Feminismo y la subversión de la identidad (1990), Butler presentó su teoría sobre la performatividad del género, ampliando el análisis en obras posteriores. Dicha perspectiva abrió la puerta a una reducción de la presión ejercida por las normas de género, con el fin de posibilitar, lo que la autora define como, una vida más vivible. Durante su carrera académica, Butler no solo ha trabajado temas de género, sino que ha ampliado sus análisis a cuestiones éticas, de filosofía política o de derechos humanos.

En el libro Cuerpos aliados y lucha política: Hacia una teoría performativa de la asamblea, Butler desarrolla su teoría de la performatividad incluyendo lo que Arendt definía como "acciones concertadas". Para ello, la autora realiza un análisis normativo de la realidad a partir de los movimientos sociales que han tenido lugar en todo el mundo en los últimos años, como Occupy Wall Street, la ocupación de la plaza Tahrir o el movimiento Black Lives Matter.

A lo largo de los seis capítulos que constituyen el libro, la autora incluye los actos corporales dentro de la teoría de la performatividad. Para dicho estudio, Butler establece un diálogo con las aportaciones de autores como Hannah Arendt o Theodor Adorno. 
En el primer capítulo, la autora parte de las acciones performativas individuales para presentar la asamblea como un "ejercicio performativo de su derecho a la aparición, es decir, una reivindicación corporeizada de una vida más vivible" (Butler, 2017, p. 31). A continuación, expone como en las movilizaciones en las que se reclama un espacio público existen elementos comunes, en ellas, las personas excluidas y que viven situaciones de precariedad se unen y se movilizan. En el tercer capítulo, centra su análisis en cómo, aunque los acontecimientos son locales, existe una reversibilidad de lo próximo y lo distante en las exigencias éticas. En el siguiente capítulo, Butler realiza un análisis de la vulnerabilidad a partir del estudio y la vinculación de la vulnerabilidad del cuerpo, las alianzas con otras personas y la política de la calle. En el capítulo cinco, la autora debate sobre qué individuos configuran el "pueblo" y cómo se manifiesta. En este debate, Butler entiende estas acciones de reclamo del espacio público como actos performativos. Finalmente, Judith Butler trabaja en torno a la pregunta " ¿se puede llevar una buena vida en medio de una mala vida?” (Butler, 2017, p. 195) vinculándola con la participación política, la vulnerabilidad y la interdependencia entre las personas para llevar una buena vida.

El libro nos permite reflexionar sobre la soberanía popular y los movimientos sociales, desde una nueva perspectiva teórica. Dicha reflexión resulta de interés para ámbitos académicos, como la ciencia política o la sociología, por ejemplo, y a la vez para aquellos actores envueltos en acciones sociales.

\section{Referencias}

Butler, J. (1990). El género en disputa. El feminismo y la subversión de la identidad. Barcelona: Paidós.

Butler, J. (2017). Cuerpos aliados y lucha política. Hacia una teoría performativa de la asamblea ( $1^{\mathrm{a}}$ edición). Barcelona: Paidós Básica

Teresa Plaja Viñas, Universidad de Barcelona teresa.plaja@ub.edu 